\title{
Reflections on Health of Young Adults with Spina Bifida: The Contradictory Path towards Well-Being in Daily Life
}

\author{
Hanna Gabrielsson1,2*, Malin Karlberg Traav²,3, Agneta Cronqvist² \\ ${ }^{1}$ Spinalis Clinic, Rehab Station Stockholm, Stockholm, Sweden \\ ${ }^{2}$ Department of Health Care Sciences, Ersta Sköndal University College, Stockholm, Sweden \\ ${ }^{3}$ ENT Department, Örebro University Hospital, Örebro, Sweden \\ Email: ${ }^{*}$ hanna.gabrielsson@esh.se
}

Received 15 March 2015; accepted 28 March 2015; published 31 March 2015

Copyright (C) 2015 by authors and Scientific Research Publishing Inc.

This work is licensed under the Creative Commons Attribution International License (CC BY). http://creativecommons.org/licenses/by/4.0/

(c) (i) Open Access

\section{Abstract}

Background: An individual with SB needs to deal with long standing illnesses and is often viewed as having a disability that needs to be compensated for. This medical condition is an example of malfunction of the body, though congenital, and could be seen as an outside-perspective to the individual human being. It is important that the required medical treatment is offered to an individual with SB, but such medical treatment alone would not encompass the full health spectrum for an individual in this specific situation. A question to be raised is how this specific group of individuals experience health. Aim: To describe the experience of daily life for young adults with SB through a theoretical lens of health. Method: This qualitative study was conducted using a reflective lifeworld approach with an interpretive part. In the lifeworld theory it is understood that all our doings, feelings and thoughts are experienced through the lifeworld. The interview questions were open and non-standardised. Findings: The main theme was formulated as The contradictory path towards well-being in daily life, and was constructed on the sub-themes: Not understanding and taking responsibility for the lower body, Having people standing behind me-not being allowed to grow up myself, Compared to people like me, I usually do well, I thought it would work out by itself, and A lack of structure in daily life. Conclusion: The study indicates that young adults with SB have a diminished health and well-being and that they have a contradictory path to travel towards independency which is of great concern for this group of individuals. Differences in views of independence constitute a problem and it is important for health care providers to be aware of the individuals' perspective on independence. This notion is something that needs to be taken into account when designing support programs for these individuals.

"Corresponding author.

How to cite this paper: Gabrielsson, H., Traav, M.K. and Cronqvist, A. (2015) Reflections on Health of Young Adults with Spina Bifida: The Contradictory Path towards Well-Being in Daily Life. Open Journal of Nursing, 5, 303-312. 


\section{Keywords}

\section{Spina Bifida, Adults, Health, Qualitative Study}

\section{Introduction}

The perception of health and its implications is profound in today's society. However, the concept of health as a state of complete physical, mental and social well-being and not only the absence of disease or injury, as formulated by WHO in 1948 [1], is not considered to help promote this understanding in society. Being born with a life-long health condition such as spina bifida (SB) raises questions relating to the perception of health in that specific situation. SB is a congenital birth defect with multisystem involvement and subsequent health condition that persists throughout life [2]. The development and refinement of symptomatic treatment during the last decades has increased life expectancy but there is still an overshadowing mortality risk for adults having SB [3].

The daily life for individual with SB involves aggravated bodily symptoms such as pain, stiffness, problems with balance and fatigue [4] [5]. They have physical disabilities (due to paralysis) which may restrain them from easily moving about as well as being dependent on a wheel chair for transportation. Often the individuals have a diminished bladder - and/or bowel function that calls for strict adherence to routines for emptying bladder and bowel but also for preventive measures to support a smooth stool and avoid constipation and hygienic handle of urine catheters to avoid urinary tract infections. Most individuals with SB have a diminished bodily sensation and therefore are not able to feel when the skin is at risk for pressure sores [6]. Such sores primarily develop on the individuals' but and feet and are therefore not easy to notice or inspect for the individuals themselves. Furthermore, individuals may have problems with taking initiatives, performing tasks, completing projects and general decision making due to cognitive impairment [7]. This so called executive dysfunction is the most common type of cognitive impairment contributing to issues of moving to independent living and performing selfcare [8] [9]. A large group of individuals with SB experience depression and anxiety [10]. To participate in society and to have some means of living is of concern for these individuals with specific needs. In Sweden the number of individuals living with SB and disability pension has markedly increased since the year 2000 [11]. To be in full-time employment is unusual and those being part-time employed are dependent on disability pension to a varying degree [11] [12]. Although positive experiences of being employed they may experience negative attitudes, ignorance and being stigmatised by their appearance and not by their personality (see for example [13] \& [14]). When individuals with SB face adolescence and early adulthood their own responsibility of the aforementioned health conditions needs to be dealt with. Growing up, even without long-term health conditions, is in itself a challenge for the development of cognitive skills and handling problems related to the process of growing. Buran et al. [15] reported that adolescents with SB are not fully engaging in activities as their age peers in for example decisionmaking, friendship activities and household responsibilities. Soe et al. [16] suggest that young adults with SB reach developmental milestones years later than their "healthy" peers. These individuals exhibit unhealthy behaviors, such as eating less healthy diets, exercising less and are prone to a more sedentary life style than age-matched adults (ibid.). These unhealthy behaviors put them at risk for developing life-style related illness [17] [18]. Furthermore, inhibited in social participation is experienced by young adults with SB and the main reasons for this is physical impairment and incontinence of bladder and bowel [19] [20]. For individuals with SB it is crucial to have access to support when growing up. Specific programs (also one web site) have been developed aiming at gathering knowledge to support this group and their relatives [18] [21]-[23]. Of special concern in the programs are practices to help facilitate independence, enhance participation in society, and increase access to effective health care aiming to increase the number of individuals living healthy lives with minimal associated health conditions.

Perception of health The previously mentioned concept of health by WHO [1] has been debated for several years and is mostly viewed as an ideal notion, something for society to strive towards. Several views on health exist and two standpoints are of interest: health as the absence of disease (a biological function) and health as an ability [24]. Health as a biological function from a notion of a naturally functioning individual, meaning that a person is healthy if all her/his organs function completely. Health as ability is an action-theoretic concept in which health is seen as a foundation for achievement (ibid.). Nordenfelt stated that a person is healthy if he/she has the ability to realize his/hers vital goals given accepted circumstances [25]. In Dahlbergs and Segestens 
empirical and existential analysis of health they state that health is a multidimensional experience [26]. More specifically they suggest "Health could be understood in terms of feel good and to be able to implement what you consider to be value in life, both large and small." (authors interpretation [26] s 53). This could be understood as experience of health being related to a general feeling of well-being and there is an interweaving of both the biological foundation of the human being and the existential dimension of being in a world together with others. The biological foundation is articulated through signs of disease and at times of being a serious and life-long condition, can constitute an outer perspective. According to the existential dimension of health we could know that despite the presence of disease an individual can strive for well-being resulting in some sort of health perception (ibid.). In this study the focus on health is from the above described existential perspective, incorporating also an inner perspective.

\section{Problem Statement}

An individual with SB needs to deal with long standing illnesses and is often viewed as having a disability that needs to be compensated for. This medical condition is an example of malfunction of the body, though congenital, and could be seen as an outside-perspective to the individual human being. This perspective includes diagnosis and treatment. It is of course of unequivocal importance that the required medical treatment is offered to an individual with SB, but such medical treatment alone would not encompass the full health spectrum for an individual in this specific situation. Furthermore, growing up and facing adulthood is in itself a necessary process to learn how to handle becoming a mature adult, and for individuals with SB this process is associated with additional efforts in terms of medical treatment, (re-)habilitation and self-care. In such situations a question can be raised how this specific group of individuals experience health. Thus the aim of the present study was to describe the experience of daily life for young adults with SB through a theoretical lens of health.

\section{Methods}

This qualitative study was conducted using a reflective lifeworld approach with an interpretive part. Reflective lifeworld research, as an offspring from phenomenological philosophy, is concerned with life experiences [27]. In the lifeworld theory it is understood that all our doings, feelings and thoughts are experienced through the lifeworld.

\subsection{Participants}

Included were adults with SB enrolled in a clinic specializing in spinal cord injuries. Individuals who did not speak or understand Swedish, or had an established intellectual disability (assessed IQ $<70$ ), were excluded. Eight individuals were asked by telephone to participate; two declined, giving a final group of six respondents between 28 and 44 years, four men and two women. All participants used a wheelchair though some walked short distances indoors. All had treated hydrocephalus. Among the six responders one lived with a partner, two lived with their parents and three lived on their own (one with personal assistant). One respondent had full-time job, one worked part-time in a family business, one were studying and three had neither jobs nor other employments.

\subsection{Data Collection}

The participants received written information about the study, emphasizing confidentiality, voluntary participation, and the recording of the interviews. All the interviews were conducted at the clinic by the participant's own choice. Each interview began with the question Can you please tell me about a good day? The interviews were conducted according to principles of reflective lifeworld research with flexibility and openness to the informants' answers [27]. Follow-up questions were asked, for example, tell me more about it or what does that mean?, to deepen the interview and to get rich data. The interviews were carried out (HG) in a separate room, lasted 60 90 minutes and were audiotaped and accordingly transcribed verbatim.

\subsection{Data Analysis}

The first phase of the analysis began with naïve reading of the transcribed interviews to get a picture of the whole. It proved to be a very rich material that required a tool for the analysis. The tool used for this part of the analysis was an emerging theory of health by Dahlberg and Segesten [26]. The concepts used in the analysis is presented in Table 1. 
Table 1. Concepts of health and its descriptions used in the analysis.

\begin{tabular}{|c|c|}
\hline Concept & Description \\
\hline Health & $\begin{array}{l}\text { Human health is the overall goal in caring, including supporting and strengthen people's health } \\
\text { processes both biologically and existentially. }\end{array}$ \\
\hline Existence and well-being & The biological health intertwined with the existential experience. \\
\hline Finding a place in existence & Living in the world in a way that both affirms one's own way of being and an existential context. \\
\hline Vitality & $\begin{array}{l}\text { Life force is essential to be able to live a life full of obstacles and opportunities. Support and strengthen } \\
\text { viability. }\end{array}$ \\
\hline Life rhythm & Possibility of movement in life. An ability and sense of "being able to". Also includes stillness and rest. \\
\hline Meaning and context & Human longing for meaning and context and how this desire is connected to health, suffering and illness. \\
\hline
\end{tabular}

Thereafter the text was coded according to these concepts. The codes with corresponding meaning units where brought together into text units and constitute the next level of analysis. The text units were analysed according to the content. Approximately ten text units were outlined. In the next phase of analysis these groups were processed down to five themes and an overarching main theme: Not understanding and taking responsibility for the lower body, Having people standing behind me-not being allowed to grow up myself, Compared to people like me, I usually do well, I thought it would work out by itself, and A lack of structure in daily life. Finally an overarching main theme was constructed: The contradictory path towards well-being in daily life.

\subsection{Trustworthiness}

Two precautions were taken to ensure the trustworthiness of the findings. First, during the analysis all steps were discussed within the research group in order to reach agreement on how data were to be sorted and labeled. Secondly, the transcribed interviews were read through again to identify any contradictions regarding the emergent themes [27].

\subsection{Ethical Considerations}

Before the interview the author again asked whether the participant still agreed to be interviewed. Participants were again informed that they could cancel the interview at any time. The study was approved by the Regional Ethical Review Board Stockholm (Dnr: 2010/761-31/5).

\subsection{Findings}

The main theme, The contradictory path towards well-being in daily life, reflects the complex situation facing adulthood with SB. This theme constitute the five themes: Not understanding and taking responsibility for the lower body, Having people standing behind me - not being allowed to grow up myself, Compared to people like me, I usually do well, I thought it would work out by itself, and A lack of structure in daily life.

\subsection{Not Understanding and Taking Responsibility for the Lower Body}

In many cases having grown up with SB means that there is a physical limitation that prevents access to ones own body especially the lower part. The respondents stated that they sometimes found it difficult to feel when something in the body was not as it should be. As one respondent said:

It didn't work out in the long run, that I was careless with myself. Ignorance of hygiene and health, it made me sick. But still I continued, I did not quite grasp how important it was. Even though I got sick and had to take a lot of medication, and that was not particularly fun. But the fact that I spent a lot of time in hospital was a safety valve for me. - Health services are there [for me]. Things will work out anyway. (1)

The quote illuminates the difficulty of learning to understand a failing body and its signals; for example, to understand the urge to urinate but still be unable to sense it and to do so without a catheter. It evidently takes a 
long time to learn when to react to this kind of "absent” body part. Although for this respondent the heath services was experienced as a safety valve.

\subsection{Having People Standing Behind Me-Not Being Allowed to Grow up Myself}

Growing up with SB appeared to some respondents as constantly having someone to help when needed even without having to ask. A respondent expressed this as follows:

My whole life I've had people at my back, so to speak. There have always been people who have supported and covered up, or not covered up, but helped me. So I've never had to ask for help, 'cause the help has always been there, since I was little, so doing things by myself and making sure to get things done, it's very hard for me. That's something I need to practice, that's something I'm going to practice and that will get better, I'm pretty... or very... confident, it's not permanent so to speak, it's all about habit. (I1)

To have had people at one's back seems to have affected the informants' independence and thus their ability to acquire important experiences independently. A lack of challenges in life was present from time to time. One respondent compared himself with his siblings and described the feeling of being over-protected and thereby unable to learn from his own mistakes. To have had people at one's back—not being allowed to grow up oneself, because of concerns received from one's closest family and others. To be helped without being asked was evidently a major problem and could be seen as a "gesture" that was perceived as being pitied.

\subsection{Compared to People Like Me, I Usually Do Well}

Several of the respondents looked back on their childhood, comparing themselves with others in similar situations, and some reported that they noticed differences in independence and in response from the environment. Ambivalence about socialising with other people in similar situations was expressed, apparently mainly because the "other" people with SB were seen as worse off in their disability, both physically and cognitively. The respondent below described — one of these "others" with SB—also was treated by the environment in a way that was not appreciated by the respondent:

Many of them had not only physical but, I noticed of course even when I was a child, that they were different in various other ways. Plus, many of them are treated, and I think that's still wrong, as raised to the skies. They get an image of the world that is a bit wrong I think (...) those kids were treated in a way that I did not actually like...I thought that was so hard to watch. (I3)

Meeting others in similar situations did not always, turn out to be distancing. Some respondents expressed a desire to meet people in similar situations. This emerged as a source of fellowship and sharing of similar experiences. Relating to other individuals with similar life situations seems to be a twofold experience.

\subsection{Thought It Would Work out by Itself}

During the interviews the informants stated that their viability and capacity to implement large and small life projects often had been disturbed by physical barriers such as obstacles in the physical environment, and additionally hampered by their inability to make things happen. These barriers were built up within the individual. Under the theme I thought it would work out by itself the respondents described the above-mentioned obstacles and opportunities that facilitated everyday life and created the conditions for being able to make things happen. This respondent described how he looked forward to moving away from home and thought that everything would work out by itself:

Because I wanted to leave home. Mostly. I even thought that everything would work out by itself if I only got away from my parents, Mom and Dad, so. I thought that I would know how to do everything by myself, that it would already be fixed. But it was not really so. Everything turned out wrong. I didn't handle it properly, and I didn't tell anyone else to handle it for me. Household, washing, it wasn't any good. The staff at school had to tell me to get it done, the dishes and the washing. Even my health, I ignored it, and the consequences were urinary tract infection and of course I became less independent and less free. (I1)

The respondents expectations were not met which was experienced as a big surprise. The desire for independence, the same as contemporaries, was not fulfilled and accordingly the situations were experienced pacifying. 
Thereby it was difficult to "get things done”, for example, take responsibility for daily meals.

\subsection{A Lack of Structure in Daily Life}

Structure in daily life could be to have a regular employment or something else as means of living. In this study one informant had a full-time job and one worked part-time in a family business; one was studying whereas still others had neither jobs nor other employment. Lack of employment was expressed as lack of natural rhythm and balance in life. Lack of employment also affected self-image and self-esteem and contributed to isolation. When informants were employed the occupation or job also created natural meeting places and social spaces. Several said that they spent much time at the computer. The computer accounted for a feeling of security, a form of activity in the absence of something else and meaningful to do. It seemed to be harder to get routines and structure in one's life without work:

It's mostly to get routines. To have something to do during the day. Yes, but just this getting up in the morning, getting ready, going off to work, coming home, eating, yes, doing what you want in the evening, whatever it might be, going to bed, up in the morning and so on. To obtain a pattern in life. For as things are now, then I can, like, nah, I'll do it tomorrow, I'll do it tomorrow, sweep it under the carpet so to speak. Which is not so good. (I2)

Daily employment serves as a platform for social contact and the feeling of context. Feelings of depression and lacking the will to do anything and mostly sitting at home feeling sorry for oneself, were described as being the consequence of not working. Likewise, opportunities for social contact and the feeling of living "normally" emerged when work was available. The feeling of being stuck and not getting ahead in life, despite a job at his father's company, was described by one informant. Taking the step out of there was described as terrifying. Employment or job is an opportunity for connection, which many in the present group lacked. Several expressed that they at various times felt that they were in a context, which was experienced as positive. Going to school, being at a gym or spending time with family and friends could contribute to a feeling of being in a context. To uphold a structure in the daily life could be facilitated if a person has a relationship. Some of the respondents had a relationship and some expressed a desire to meet someone.

\subsection{The Contradictory Path towards Well-Being in Daily Life}

The main theme reflects the complex situation individuals with SB are in, when they are pursuing "living independently". This expression means for this specific group means taking part in decisions based on one's own possibilities. The contradiction inherent to the process of one's own adult life concerns succeeding to become independent, even when you are dependent on others. The present group were living in bodies that functioned in a different way. To understand such a body good cognitive abilities are required, but for these individuals with SB and cognitive limitations it is a specific challenge, which is described in the theme Not understanding and taking responsibility for the lower body. Growing up with this disability means growing up with people "at one's back", helping sometimes needlessly, which complicated the process of developing the skills of independence as the theme Having people behind me - not being allowed to grow up myself highlight. Having had people behind you cause the individual with SB to "choose" the easy road, waiting for help, rather than actively seeking opportunities and solutions to the actual problem. The theme Compared to people like me, I usually do well, can also be understood as a contradiction concerning the conflicting feelings about being with others with $\mathrm{SB}$. The theme I thought it would work out by itself elucidates the tension between the individuals' desire to become independent and finding oneself not being able to. This is of course related to similar aspects described under the theme Having had people behind me - not being allowed to grow up myself. To have had people in the background could contribute to a "learned helplessness", which then became an obstacle to independence. To be helped without being asked was raised as a problem, and is in itself a paradox in terms of independence. It shows a vulnerability where individuals also need to respond to an environment that takes the need for help for granted. One difficulty lies in seeing yourself as an independent individual while the environment persists in seeing something else. Furthermore, it is difficult to structure everyday life without employment, which links the need for structure and schedule in the theme A lack of structure in daily life. When you don't have anywhere to go during the days or nothing specific to do, it's hard to feel needed and it makes it harder to develop routines. 


\section{Discussion}

The present aim was to describe the experience of daily life for young adults with SB through a theoretical lens of health. The main theme The contradictory path towards well-being in daily life reflects the problematic movement towards adulthood for this group. The subthemes substantiate this theme and whereas the informants had a limited understanding of their body and its limitations, they felt they had people standing behind their backs which contributed to a feeling of not being able to grow. However when they compared themselves with other individuals with similar conditions they felt they did well but at the same time they thought that problems would work out by themselves. Finally, the lack of structure in daily life constitutes a barrier towards independence.

The theme Not understanding and take responsibility for the lower body point out that the time frame was of significance for this understanding and responsibility. One explanation can be that having impaired physical functions from birth with sparse sensations diminishes the possibilities to even recognize that something is wrong. Adding a cognitive impairment makes it even more complicated for the individual to fully understand the situation.

Another dimension of the experience of growing up involves who you are, self-knowledge and how well you understand yourself and your interaction with the outside world and other people. In the present study the awareness was initiated by the consequences of lack of insight, for example, not contacting health care when needed.

Informants expressed not having been allowed to grow and develop themselves and always having had people around to back them up, described under the theme Having people behind me-not being allowed to grow myself. Some referred to habit, saying that habits would change with a move to one's own accommodation. Note that all the present informants were adults, aged 28 and older. Adults are generally expected to be independent, even if this includes the support and resources to organize everyday life on their own terms.

In this study some informants expressed ambivalence about socializing with others with SB, as described in the theme Compared to people like me I usually do well. It may be difficult to feel attached to people one believes have a more serious disability, or if one spends most of one's time with non-disabled people. The absence of role models with disabilities may contribute to difficulties in accepting one's disability. To find others with SB that have more difficulties than yourself and who are being treated in a way that you do not wish to be treated, can certainly contribute to the rejection of other individuals with SB. Other informants had, rather, a desire to meet others in similar situations because this created a sense of community and shared experience.

The themes I thought it would work out by itself and A lack of structure in daily life are intertwined. First, the situation with obstacles in the physical environment and the individuals' inability to make things happen is illustrated in the theme I thought it would work out by itself. This could be interpreted as pacifying and that the individual ends up not taking initiatives and stagnation takes place. Adding on to this pacifying situation is if the individual experience some form of anxiety or have decision problems. Prevalence of anxiety and depression in this group has been reported by Bellin et al. [28]. A way of counteracting the pacification was for the individuals to schedule their everyday life to make things happen. This can be seen as self-evident when one has cognitive difficulties. However, this appeared to be an insight that informants had reached in adulthood. Second, in the theme A lack of structure in daily life the importance of having somewhere to go during the day, is described. Getting professional assistance was mentioned as essential for having a structure in daily life and for being able to leave home, which also affected self-esteem and the feeling of being free.

To become independent as part of growing-up is normally a struggle even for non-disabled adolescents. To become independent while being dependent of others seems to be an additional challenge for individuals with SB. Similar findings have been made in a study by Ridosh et al. [29] who also state that the transition to independence is delayed. Furthermore Ridosh et al. [29] state that most of their participants were lacking peer support and relationships during the transition to adulthood. Strong peer relationships and support were seen as prompting factors for building inner strength, for example through sport activities. This is similar to the findings in the present study where being in a context, for example at a training center, is seen as an opportunity to socialize.

As we described above some individuals in the present study did not have anything to do or somewhere to go during the day, which contributed to experiences of lack of context. According to Dahlberg [30] a lack of context and connection relate to involuntary loneliness i.e. not belonging to anyone or anything and a lack of participation in the world. In the present study informants expressed ambiguous feelings towards being with other SB individuals especially when those were treated as raised to the skies. They felt strange about being viewed as 
being similar.

Dahlberg [30] means that this "loneliness with others" may involve the feeling of being different. One does not belong to others when at the same time being different. This dimension of being lonely with others constitutes a more apparent element of isolation than when there are no others around (ibid). Loneliness can also be voluntary and then constitute restfullness and creativeness. This volontary loneliness may involve a lack of tangible context, but a context could still "be" available, like nature or animal fellowship (ibid.). Volontary loneliness can be expressed as solitude and Long and Averill [31] comment that individuals while having biological needs of attachement and affiliation search a state of solitude to reflect over self and being with others. A question to be raised is to what extent this group of individuals with SB search a state of solitude to reflect on life and well-being. Of course those who experience isolation do not seek solitude to contemplate over life.

Health may be viewed as two dimensional with one biological part which for these individuals is a birth defect. According to Dahlberg et al. [26] the understanding of health does not necessarily exclude illness, but the individual needs to be able to handle and relate to illness or other health related problems, and be able to experience health in terms of well-being and a sense of "being able to". The results show that individuals in the present study are experiencing problems with understanding and taking responsibility for the lower body as well as not always "being able to", which makes it hard to state that health and well-being is present. The situation can be compensated by individual organized support in terms of professional assistance. This is not to say that individuals with SB getting assistance gain increased health and well-being. To increase well-being it is necessary for the individual to reflect on possibilities and wishes to acknowledge that they actually are able to do things. There is reason to believe that the two dimensions of health are interrelated, that is having severe biological dysfunction will influence the existential dimension of health and vice versa.

In this study we have chosen to use a theoretical standpoint of health as an analytic tool. From this standpoint health is articulated as well-being and emanates from phenomenological philosophy especially the existential view [32]. We have used concepts emerged within this view early in the analysis and we do not claim that we have validated this theoretical view. By doing so however, we have gained more knowledge about the daily-life of young adults with SB. Further, we do not claim that this study has been guided by the principles of reflective life-world research, articulated by Dahlberg, Dahlberg \& Nyström in 2008 [27] that puts forward the phenomenological openness through all the steps in the research process. This study is based on the life-world theory in the way that it has influenced the design of the study: theoretical standpoint, problem statement, interview questions and analysis.

\section{Conclusions and Practical Implications}

The study indicates that young adults with SB have a diminished health and well-being and that they have a contradictory path to travel towards independency. To become independent is a wide-spread problem for this group of individuals. For the striving towards independence it is essential to get professional support, but it is important to recognize that different surrounding actors, including the individuals themselves, may have different views of what independence means. Differences in views of independence constitute a problem and it is important for health care providers to be aware of the individuals' perspective on independence. This should be taken into account when designing support programs for individuals with SB.

\section{Acknowledgements}

Special thanks to the Carolina Montgomery Foundation, the Spinalis Foundation and the Spinalis Clinic at Rehab Station Stockholm for funding and support.

\section{Declaration of Conflicting Interests}

The authors declare that they have no potential conflict of interest with respect to the research, authorship or publication of this article.

\section{Authors' Contributions}

Study design: HG, MKT, AC; data collection: HG; data analysis: HG, MKT, AC and manuscript preparation: HG, MKT, AC. 


\section{References}

[1] WHO (1948) Constitution of the World Health Organization. Official Records of the World Health Organization, 2, 100.

[2] Dicianno, B.E., Kurowski, B.G., Yang, J.M.J., Chancellor, M.B. Bejjani, G.K., Fairman, A.D., Lewis, N. and Sotirake, J. (2008) Rehabilitation and Medical Management of the Adult with Spina Bifida. American Journal of Physical Medicine \& Rehabilitation, 87, 1026-1050. http://dx.doi.org/10.1097/PHM.0b013e31818de070

[3] Oakeshott, P., Hunt, G.M., Poulton, A. and Reid, F. (2010) Expectation of Life and Unexpected Death in Open Spina Bifida: A 40-Year Complete, Non-Selective, Longitudinal Cohort Study. Developmental Medicine \& Child Neurology, 52, 749-753. http://dx.doi.org/10.1111/j.1469-8749.2009.03543.x

[4] Werhagen, L., Gabrielsson, H., Westgren, N. and Borg, K. (2013) Medical Complication in Adults with Spina Bifida. Clinical Neurology and Neurosurgery, 115, 1226-1229. http://dx.doi.org/10.1016/j.clineuro.2012.11.014

[5] Törnbom, M., Jonsson, U. and Stibrant Sunnerhagen, K. (2013) Increasing Symptoms, Met and Unmet Needs in Adults with Cerebral Palsy or Meningomyelocele a Longitudinal Follow-Up. Scandinavian Journal of Disability Research, 15, 249-263. http://dx.doi.org/10.1080/15017419.2012.703968

[6] Ottolini, K., Harris, B., Amling, K.J., Kennelly, A.M., Phillips, L.A. and Tosi, L.L. (2013) Wound Care Challenges in Children and Adults with Spina Bifida: An Open-Cohort Study. Journal of Pediatric Rehabilitation Medicine: An Interdisciplinary Approach, 6, 1-10. http://dx.doi.org/10.3233/PRM-130231

[7] Han, S.D., Delis, D.C. and Holdnack, J.A. (2008) Extending the WISC-IV: Executive Functioning. In: Prifitera, A., Saklofske, D.H. and Weiss, L.G., Eds., WISC-IV Clinical Assessment and Intervention, Academic Press, San Diego, 497-515.

[8] Mahone, E.M. and Bernstein, J.H. (1993) Toward a Developmental Neuropsychology: The Case of Myelodysplasia. Poster Presented at the Massachusetts Neuropsychological Society Annual Research Conference, Boston.

[9] Rose, B.M. and Holmbeck, G.N. (2007) Attention and Executive Functions in Adolescents with Spina Bifida. Journal of Pediatric Psychology, 32, 983-994. http://dx.doi.org/10.1093/jpepsy/jsm042

[10] Kalfoss, M. and Alve, S. (2003) Self-Reported Psychological Distress: An Outcome that Matters for CommunityResiding Adults with SB. European Journal of Pediatric Surgery, 13, 42-44.

[11] Törnbom, M., Lundälv, J., Jesperson, A., Stibrant Sunnerhagen, K. and Grimby, G. (2011) Occupations and Means of Living in Adults with Cerebral Palsy or Meningomyelocele during Two Decades in Sweden. Scandinavian Journal of Disability Research, 13, 21-35. http://dx.doi.org/10.1080/15017411003711791

[12] Leger, R.R. (2005) Severity of Illness, Functional Status, and HRQOL in Youth with SB. Rehabilitation Nursing, 30, 180-188. http://dx.doi.org/10.1002/j.2048-7940.2005.tb00107.x

[13] Van de Ven, L., Post, M., de Witte, L. and van den Heuvel, W. (2005) It Takes Two to Tango: The Integration of People with Disabilities into Society. Disability \& Society, 20, 311-329. http://dx.doi.org/10.1080/09687590500060778

[14] Törnbom, K., Törnbom, M. and Stibrant Sunnerhagen, K. (2013) Experiences of Participation in a Swedish Society among Adults with Cerebral Palsy or Spina Bifida: Involvement and Challenges. Journal of Social Work in Disability \& Rehabilitation, 12, 256-271. http://dx.doi.org/10.1080/1536710X.2013.834783

[15] Buran, C.F., Sawin, K.J., Brei, T.J. and Fastenau, P.S. (2004) Adolescents with Myelomeningocele: Activities, Beliefs, Expectations, and Perceptions. Developmental Medicine \& Child Neurology, 46, 244-252. http://dx.doi.org/10.1111/j.1469-8749.2004.tb00479.x

[16] Soe, M.M., Swanson, M.E., Bolen, J.C., Thibedeau, J.K. and Johnson, N. (2012) Health Risk Behaviors among Young Adults with Spina Bifida. Developmental Medicine \& Child Neurology, 54, 1057-1064. http://dx.doi.org/10.1111/j.1469-8749.2012.04402.x

[17] Buffart, L.M., van den Berg-Emons, R.J., Burdorf, A., Janssen, W.G., Stam, H.J. and Roebroeck, M.E. (2008) Cardiovascular Disease Risk Factors and the Relationships with Physical Activity, Aerobic Fitness, and Body Fat in Adolescents and Young Adults with Myelomeningocele. Archives of Physical Medicine and Rehabilitation, 89, 2167-2173. http://dx.doi.org/10.1016/j.apmr.2008.04.015

[18] Roebroeck, M.E., Jahnsen, R., Carona, C., Kent, R.M. and Chamberlain, M.A. (2009) Adult Outcomes and Lifespan Issues for People with Childhood-Onset Physical Disability. Developmental Medicine \& Child Neurology, 51, 670-678. http://dx.doi.org/10.1111/j.1469-8749.2009.03322.x

[19] Edwards, M., Borzyskowski, M., Cox, A. and Badcock, J. (2004) Neuropathic Bladder and Intermittent Catheterization: Social and Psychological Impact on Children and Adolescents. Developmental Medicine \& Child Neurology, 46, 168177. http://dx.doi.org/10.1017/S0012162204000301

[20] Barf, H.A., Post, M.W.M., Verhoef, M., Jennekens-Schinkel, A., Gooskens, R.H.J.M. and Prevo, A.J.H. (2009) Restrictions in Social Participation of Young Adults with Spina Bifida. Disability and Rehabilitation, 31, 921-927. 
http://dx.doi.org/10.1080/09638280802358282

[21] Holmbeck, G.N., Alriksson-Schmidt, A.I., Bellin, M.H. and Devine, K.A. (2010) A Family Perspective: How This Product Can Inform and Empower Families of Youth with Spina Bifida. Pediatric Clinics of North America, 57, 919934. http://dx.doi.org/10.1016/j.pcl.2010.07.012

[22] Thibadeau, J.K., Alriksson-Schmidt, A.I. and Zabel, T.A. (2010) The National Spina Bifida Program Transition Initiative: The People, the Plan, and the Process. Pediatric Clinics of North America, 57, 903-910. http://dx.doi.org/10.1016/j.pcl.2010.07.010

[23] West, C., Brodie, L., Dicker, J. and Steinbeck, K. (2011) Development of Health Support Services for Adults with SB. Disability and Rehabilitation. Early Online, 1-8. http://www.aci.health.nsw.gov.au/_data/assets/pdf_file/0010/155773/spina_bifida.pdf

[24] Nordenfelt, L. (2006) Animal and Human Health and Welfare: A Comparative Philosophical Analysis. CAB International, Wallingford, UK.

[25] Nordenfelt, L. (1995) On the Nature on Health. 2nd Revised Edition, Kluwer Academic Publishers, Dordrecht.

[26] Dahlberg, K. and Segesten, K. (2010) Hälsa och vårdande I teori och praxis (Health and Caring in Theory and Practice). Natur \& Kultur, Stockholm.

[27] Dahlberg, K., Dahlberg, H. and Nyström, M. (2008) Reflective Lifeworld Research. 2nd Edition, Studentlitteratur, Lund.

[28] Bellin, M.H., Zabel, T.A., Dicianno, B.E., Levey, E., Garver, K., Linroth, R. and Braun, P. (2010) Correlates of Depressive and Anxiety Symptoms in Young Adults with Spina Bifida. Journal of Pediatric Psychology, 35, 778-789. http://dx.doi.org/10.1093/jpepsy/jsp094

[29] Ridosh, M., Braun, P., Roux, G., Bellin, M. and Sawin, K. (2011) Transition in Young Adults with Spina Bifida: A Qualitative Study. Child: Care, Health and Development, 37, 866-874. http://dx.doi.org/10.1111/j.1365-2214.2011.01329.x

[30] Dahlberg, K. (2007) The Enigmatic Phenomenon of Loneliness. International Journal of Qualitative Studies on Health and Well-Being, 2, 195-207. http://dx.doi.org/10.1080/17482620701626117

[31] Long, C.R. and Averill, J.R. (2003) Solitude: An Exploration of Benefits of Being Alone. Journal for the Theory of Social Behaviour, 33, 21-44. http://dx.doi.org/10.1111/1468-5914.00204

[32] Dahlberg, K., Todres, L. and Galvin, K. (2009) Lifeworld Led Healthcare Is More than Patient-Led Care: An Existential View of Well-Being. Medicine, Health Care and Philosophy, 12, 265-271. http://dx.doi.org/10.1007/s11019-008-9174-7 